\title{
RANCANG BANGUN PENGERING MENGGUNAKAN SISTEM ALIRAN KONVEKSI UDARA DARI KOLEKTOR SURYA
}

\author{
Oleh: \\ Fahmi Huda Z. ${ }^{1}$, Imam Tazi ${ }^{2}$
}

\begin{abstract}
ABSTRAK: Indonesia merupakan wilayah kepualauan yang menempati daerah sekitar katulistiwa serta negara beriklim tropis sehingga matahari bersinar sepanjang tahun. Kondisi ini dapat menjadikan matahari menjadi alternatif sumber energi masa depan yang tak akan habis bila digunakan sebagai sumber energi alternatif. Salah satu pemanfaatan energi surya yang banyak digunakan adalah pemanfaatannya sebagai pengering.

Tujuan penelitian ini adalah: merancang dan membuat pengering bertenaga surya sebagai sumber energi sehingga syarat kecakupan panas bisa ditingkatkan dan mengoptimalisasi panas yang diterima oleh pengering agar alat dapat menerima panas secara maksimal. Metode penelitian yang digunakan adalah perancangan dan pembuatan alat serta studi eksperimental dengan melakukan pendekatan penelitian secara deskripif. Adapun analisis penelitian dideskripsikan dari perbandingan hasil temperatur pada kotak pengering dengan variasi sudut kolektor serta hasil uji sampel menggunakan rancangan alat yang sudah didesain dengan dibedakan tambahan glaswoll (bahan perangkap panas) pada kolektor dan tanpa tambahan glaswoll.

Hasil yang diperoleh dari penelitian ini yaitu telah dirancang bangun sebuah alat pengering menggunakan sistem aliran konveksi udara dari kolektor surya yang telah dimodifikasi dengan tambahan glaswoll dan cermin pada sisi-sisi kolektor, hal ini mampu meningkatkan hasil dari kualitas temperatur pada pengering. Kolektor dengan sudut kemiringan $75^{\circ}$ memiliki nilai temperatur tertinggi pada kotak pengering, yaitu jika dengan tambahan glaswoll mengalami penguatan temperatur sebesar 207,50\% dibanding temperatur luar dan jika tidak menggunakan glaswoll mengalami penguatan temperatur sebanyak $201,80 \%$ dibanding temperatur luar. Hasil dari produk akhir bahan yang telah dikeringkan menggunakan alat pengering memiliki nilai kualitas yang lebih bagus dibanding tanpa menggunakan alat pengering, serta meningkatkan efisiensi waktu proses pengeringan yaitu 5 hari tanpa alat setara dengan pengeringan 3 hari dengan menggunakan alat.
\end{abstract}

Kata kunci : Energi alternatif, Konveksi udara, Kolektor surya, Glaswoll

\begin{abstract}
ABSTRACK: Indonesia is anarchi pelagic territory in habited the equatorial and tropical country so that the sun shines all year round. This condition can make solar a viable alternative source of energy future that will not run when it is used as an alternative energy source. One of the utilization of solar energy utilization that is widely used as a dryer.

The purpose of this studyis: to design and create a solar powered dryer as a source of heaten ergy that can be improved ad equacy requirements and optimize the heat received by the dryer so that the tool can accept the maximum heat. The method used is the design and manufacture of equipment and experimental studies with the descriptive are searc happroach. The comparative analysis of the results of the research described in the dryer box with temperature variations as well as the collector angle sample test results using a design tool that has been designed with additional differentiated glaswoll (heat trapping substance) at no additional collector and glaswoll.

The results obtained from this research that has been designed using the dry erupa convectionair flow system of solar collector that has been modified with the addition glaswoll andmirrors on the sides of thecollector it is able to improve the quality of the results of the temperature on the dryer. Collector with a slope angle of $75^{\circ}$ has avalue ofthe highest temperature in the dryer box, that is if the additional glaswoll gained $207.50 \%$ over the temperature of the outside temperature and if it does not use as much glaswoll gained $201.80 \%$ over the temperature outside temperature. Results of the final product material that has been drie dusing a dryer has avalue of better quality than without using the dryer, as well a simprove the efficiency of the drying process time is 6 days without drying equipment equivalent to 3 days by using the tool.
\end{abstract}

Keywords: alternative energy, air convection, solar collectors, glaswoll

1,2 JurusanFisikaUniversitas Islam Negeri (UIN) Maulana Malik Ibrahim Malang 


\section{PENDAHULUAN}

Kebutuhan energi dari tahun ke tahun semakin meningkat, krisis energi dan masalah lingkungan yang terjadi membuat manusia berusaha mencari sumber energi alternatif yang bersifat terbarukan dan memberi dampak minimal terhadap lingkungan.

Indonesia merupakan salah satu negara yang terletak di khatulistiwa serta negara beriklim tropis sehingga matahari bersinar sepanjang tahun Salah satu pemanfaatan energi surya yang banyak digunakan adalah pemanfaatannya sebagai pengering hasil pertanian dan bahan makanan.

Energi surya adalah bentuk energi yang berasal dari matahari yang ditimbulkan akibat radiasi cahaya matahari ke permukaan bumi. Radiasi adalah proses perpindahan panas melalui gelombang elektromagnetik atau paket-paket energi (photon) yang dapat dibawa sampai pada jarak yang sangat jauh tanpa memerlukan interaksi dengan medium (ini yang menyebabkan mengapa perpindahan panas radiasi sangat penting pada ruang vakum), disamping itu jumlah energi yang dipancarkan sebanding dengan temperatur benda tersebut. Kedua hal tersebut yang membedakan antara peristiwa perpindahan panas konduksi dan konveksi dengan perpindahan panas radiasi [3].

Pengeringan merupakan proses sederhana mengurangi kandungan air dari dalam suatu produk sampai pada tingkat tertentu, sehingga dapat mencegah pembusukan dan aman disimpan dalam jangka waktu yang lama [2].

Alat pengering surya tipe efek rumah kaca (ERK) digunakan sebagai alternatif pengganti pengeringan surya kolektor plat datar dengan biaya relatif murah. Prinsip alat pengering surya tipe ERK yaitu penggunaan bangunan transparan yang berfungsi sebagai penyekat sehingga memungkinkan radiasi gelombang pendek matahari untuk masuk dan menyekat keluar radiasi gelombang panjang. Oleh karena itu, lapisan penutup transparan memerlukan bahan yang memiliki nilai transmisivitas yang tinggi dengan absorbsivitas dan reflektivitas yang rendah [1].

Penelitian bertujuan untuk merancang dan membuat pengering bertenaga surya sebagai sumber energi sehingga syarat kecakupan panas bisa ditingkatkan dan mengoptimalisasi panas yang diterima oleh pengering agar alat dapat menerima panas secara maksimal. Metode penelitian yang digunakan adalah perancangan dan pembuatan alat serta studi eksperimental dengan melakukan pendekatan penelitian secara deskripif. Adapun analisis penelitian dideskripsikan dari perbandingan hasil temperatur pada kotak pengering dengan variasi sudut kolektor serta hasil uji sampel menggunakan rancangan alat yang sudah didesain dengan dibedakan tambahan glaswoll (bahan perangkap panas) pada kolektor dan tanpa tambahan glaswoll.

\section{HASIL DAN PEMBAHASAN}

Alat pengering dengan sumber energi surya yang telah dirancang bangun secara keseluruhan bagian-bagiannya dapat dilihat pada gambar sebagai berikut: 


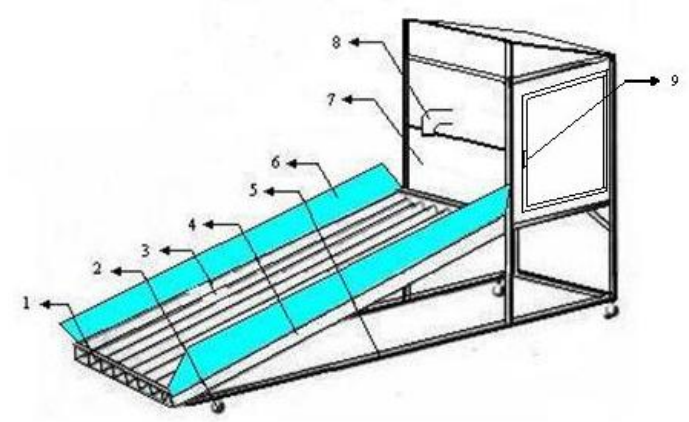

Gambar 2. Pengering dengan kolektor surya

\section{Keterangan:}

1. Rongga udara yang berfungsi sebagai jalannya udara luar untuk masuk.

2. Roda kursi yang digunakan untuk memindahkan pengering dengan mudah jika diperlukan pemindahan sewaktu-waktu.

3. Plat seng yang bergelombang yang berfungsi sebagai penangkap panas dari cahaya matahari.

4. Kayu lapis yang berfungsi penutup samping dari desain kolektor.

5. Kayu yang berfungsi sebagai kerangka pengering.

6. Cermin yang berfungsi sebagai pemerkuat tingkat radiasi yang akan diterima oleh kolektor.

7. Kayu yang bagian dalamnya telah dilapisi perangkap panas yang berfungsi melindungi bahan yang akan dikeringkan dari hal-hal yang bisa mengganggu dalam proses pengeringan serta mengisolasi panas yang ada di dalamnya.

8. Cerobong yang berfungsi tempat keluarnya suhu panas dari kolektor.

9. Pintu yang digunakan sebagai tempat keluar masuknya bahan yang akan dikeringkan.

\section{Kinerja Alat}

Kinerja alat merupakan gambaran tentang kemampuan alat dalam memerankan fungsinya terhadap percobaan dengan melihat atau mengukur parameter tertentu. Alat pengering yang digunakan dalam penelitian ini menggunakan sistem efek rumah kaca atau green house effect (GHE). Unjuk kerja alat diukur berdasarkan kemampuan dalam meningkatkan panas dengan mengukur temperatur pada beberapa sudut kolektor yang telah ditentukan dan laju pengeringan kadar air pada suatu bahan uji yang akan dibandingkan dengan hasil di lingkungan.

\section{Variasi Sudut Kolektor Menggunakan Glaswoll}

\section{Kolektor dengan Sudut $30^{\circ}$}

Temperatur ruang pengering terletak pada kisaran 48,78 $-56,62{ }^{\circ} \mathrm{C}$ dengan nilai rata-rata $52,20{ }^{\circ} \mathrm{C}$, sedangkan temperatur lingkungan dan temperatur kolektor berturut-turut berkisar antara $29,27-32,53{ }^{\circ} \mathrm{C}$ dengan nilai rata-rata $31,03{ }^{\circ} \mathrm{C}$ dan $60,44-83,12{ }^{\circ} \mathrm{C}$ dengan nilai rata-rata $73,14{ }^{\circ} \mathrm{C}$. Selisih rata-rata antara temperatur kotak pengering dengan temperatur luar adalah $21,15{ }^{\circ} \mathrm{C}$, jadi kotak pengering mengalami penguatan temperatur sebanyak $166,82 \%$ dibanding temperatur luar. 


\section{Kolektor dengan Sudut $\mathbf{4 5}^{\circ}$}

Temperatur ruang pengering terletak pada kisaran $50,14-63,85{ }^{\circ} \mathrm{C}$ dengan nilai rata-rata $59,53{ }^{\circ} \mathrm{C}$, sedangkan temperatur lingkungan dan temperatur kolektor berturut-turut berkisar antara $30,00-32,31{ }^{\circ} \mathrm{C}$ dengan nilai rata-rata $31,56{ }^{\circ} \mathrm{C}$ dan $62,25-88,99{ }^{\circ} \mathrm{C}$ dengan nilai rata-rata $81,24{ }^{\circ} \mathrm{C}$. Selisih rata-rata antara temperatur kotak pengering dengan temperatur luar adalah $27,96{ }^{\circ} \mathrm{C}$, jadi kotak pengering mengalami penguatan temperatur sebanyak $188,60 \%$ dibanding temperatur luar.

\section{Kolektor dengan Sudut $60^{\circ}$}

Temperatur ruang pengering terletak pada kisaran 55,01 $-67,81{ }^{\circ} \mathrm{C}$ dengan nilai rata-rata $61,65{ }^{\circ} \mathrm{C}$, sedangkan temperatur lingkungan dan temperatur kolektor berturut-turut berkisar antara $29,84-32,31{ }^{\circ} \mathrm{C}$ dengan nilai rata-rata $30,94{ }^{\circ} \mathrm{C}$ dan $74,00-97,29{ }^{\circ} \mathrm{C}$ dengan nilai rata-rata $85,25^{\circ} \mathrm{C}$. Selisih rata-rata antara temperatur kotak pengering dengan temperatur luar adalah $30,71{ }^{\circ} \mathrm{C}$, jadi kotak pengering mengalami penguatan temperatur sebanyak 199,24\% dibanding temperatur luar.

\section{Kolektor dengan Sudut 75}

Temperatur ruang pengering terletak pada kisaran $53,94-73,64{ }^{\circ} \mathrm{C}$ dengan nilai rata-rata $66,61{ }^{\circ} \mathrm{C}$, sedangkan temperatur lingkungan dan temperatur kolektor berturut-turut berkisar antara $30,08-33,61{ }^{\circ} \mathrm{C}$ dengan nilai rata-rata $32,10{ }^{\circ} \mathrm{C}$ dan $74,96-108,60{ }^{\circ} \mathrm{C}$ dengan nilai rata-rata $94,68{ }^{\circ} \mathrm{C}$. Selisih rata-rata antara temperatur kotak pengering dengan temperatur luar adalah $34,51{ }^{\circ} \mathrm{C}$, jadi kotak pengering mengalami penguatan temperatur sebanyak $207,50 \%$ dibanding temperatur luar.

\section{Kolektor dengan Sudut $90^{\circ}$}

Temperatur ruang pengering terletak pada kisaran $39,01-43,36{ }^{\circ} \mathrm{C}$ dengan nilai rata-rata $41,61{ }^{\circ} \mathrm{C}$, sedangkan temperatur lingkungan dan temperatur kolektor berturut-turut berkisar antara $29,29-32,14{ }^{\circ} \mathrm{C}$ dengan nilai rata-rata $30,43{ }^{\circ} \mathrm{C}$ dan $74,09-91,52{ }^{\circ} \mathrm{C}$ dengan nilai rata-rata $84,83{ }^{\circ} \mathrm{C}$. Selisih rata-rata antara temperatur kotak pengering dengan temperatur luar adalah $11,17{ }^{\circ} \mathrm{C}$, jadi kotak pengering mengalami penguatan temperatur sebanyak $136,72 \%$ dibanding temperatur luar.

\section{Kinerja Alat dengan Variasi Sudut Kolektor Tanpa Glaswoll}

\section{Kolektor dengan Sudut $30^{\circ}$}

Temperatur ruang pengering terletak pada kisaran $49,05-52,89{ }^{\circ} \mathrm{C}$ dengan nilai ratarata $78,49{ }^{\circ} \mathrm{C}$, sedangkan temperatur lingkungan dan temperatur kolektor berturutturut berkisar antara $30,88-32,27{ }^{\circ} \mathrm{C}$ dengan nilai rata-rata $31,53{ }^{\circ} \mathrm{C}$ dan $49,05-$ $52,89{ }^{\circ} \mathrm{C}$ dengan nilai rata-rata $49,44{ }^{\circ} \mathrm{C}$. Selisih rata-rata antara temperatur kotak pengering dengan temperatur luar adalah $17,91{ }^{\circ} \mathrm{C}$, jadi kotak pengering mengalami penguatan temperatur sebanyak $156,79 \%$ dibanding temperatur luar. 


\section{Kolektor dengan Sudut $45^{\circ}$}

Temperatur ruang pengering terletak pada kisaran $54,18-60,00{ }^{\circ} \mathrm{C}$ dengan nilai ratarata $55,62{ }^{\circ} \mathrm{C}$, sedangkan temperatur lingkungan dan temperatur kolektor berturutturut berkisar antara $30,59-32,51{ }^{\circ} \mathrm{C}$ dengan nilai rata-rata $31,69{ }^{\circ} \mathrm{C}$ dan $80,97-$ $90,71{ }^{\circ} \mathrm{C}$ dengan nilai rata-rata $86,73{ }^{\circ} \mathrm{C}$. Selisih rata-rata antara temperatur kotak pengering dengan temperatur luar adalah $23,92{ }^{\circ} \mathrm{C}$, jadi kotak pengering mengalami penguatan temperatur sebanyak $175,49 \%$ dibanding temperatur luar.

\section{Kolektor dengan Sudut $60^{\circ}$}

Temperatur ruang pengering terletak pada kisaran $56,06-63,39{ }^{\circ} \mathrm{C}$ dengan nilai rata-rata $58,82{ }^{\circ} \mathrm{C}$, sedangkan temperatur lingkungan dan temperatur kolektor berturut-turut berkisar antara $29,60-32,62{ }^{\circ} \mathrm{C}$ dengan nilai rata-rata $31,53{ }^{\circ} \mathrm{C}$ dan $75,90-85,33{ }^{\circ} \mathrm{C}$ dengan nilai rata-rata $81,43{ }^{\circ} \mathrm{C}$. Selisih rata-rata antara temperatur kotak pengering dengan temperatur luar adalah $27,29{ }^{\circ} \mathrm{C}$, jadi kotak pengering mengalami penguatan temperatur sebanyak $186,54 \%$ dibanding temperatur luar.

\section{Kolektor dengan Sudut $75^{\circ}$}

Temperatur ruang pengering terletak pada kisaran $58,67-71,13{ }^{\circ} \mathrm{C}$ dengan nilai rata-rata $65,89{ }^{\circ} \mathrm{C}$, sedangkan temperatur lingkungan dan temperatur kolektor berturut-turut berkisar antara $31,27-34,38{ }^{\circ} \mathrm{C}$ dengan nilai rata-rata $32,65{ }^{\circ} \mathrm{C}$ dan $80,21-99,20{ }^{\circ} \mathrm{C}$ dengan nilai rata-rata $94,07{ }^{\circ} \mathrm{C}$. Selisih rata-rata antara temperatur kotak pengering dengan temperatur luar adalah $32,24{ }^{\circ} \mathrm{C}$, jadi kotak pengering mengalami penguatan temperatur sebanyak $201,80 \%$ dibanding temperatur luar.

\section{Kolektor dengan Sudut $90^{\circ}$}

Temperatur ruang pengering terletak pada kisaran $39.68-42,73{ }^{\circ} \mathrm{C}$ dengan nilai rata-rata $40,99{ }^{\circ} \mathrm{C}$, sedangkan temperatur lingkungan dan temperatur kolektor berturut-turut berkisar antara $31,64-33,93{ }^{\circ} \mathrm{C}$ dengan nilai rata-rata $32,58{ }^{\circ} \mathrm{C}$ dan $83,44-88,15{ }^{\circ} \mathrm{C}$ dengan nilai rata-rata $85,89^{\circ} \mathrm{C}$. Selisih rata-rata antara temperatur kotak pengering dengan temperatur luar adalah $8,40{ }^{\circ} \mathrm{C}$, jadi kotak pengering mengalami penguatan temperatur sebanyak $125,80 \%$ dibanding temperatur luar.

\section{Uji Coba Pengering dengan Bahan}

Pada pengambilan data dilakukan dengan bahan uji menggunakan biji kopi cokelat yang masih basah dengan berat awal $0,25 \mathrm{~kg}$. Pengujian ini dilakukan dengan tiga cara pengeringan, yaitu: pertama menggunakan alat pengering yang telah dirancang bangun dengan tambahan glaswoll, yang kedua meggunakan alat pengering yang telah dirancang bangun namun tanpa menggunakan tambahan glaswoll dan yang ketiga pengeringan dilakukan tanpa menggunakan alat pengering atau dilakukan pengeringan secara langsung diterik matahari. Pengambilan data dilakukan sebagai berikut: jika pengambilan data menggunakan alat pengering, maka biji kopi cokelat yang telah ditimbang tersebut dimasukkan ke dalam kotak pengering dan jika dilakukan pengeringan tanpa menggunakan alat pengering maka biji kopi cokelat dikeringkan langsung di bawah terik matahari. Lama 
waktu pengeringan yang dilakukan adalah selama 5 x 24 jam yaitu pada pukul 10:00 2:00, dan diambil data beratnya setelah dilakukan pengeringan setiap harinya.

Adapun hasilnya sebagai berikut:

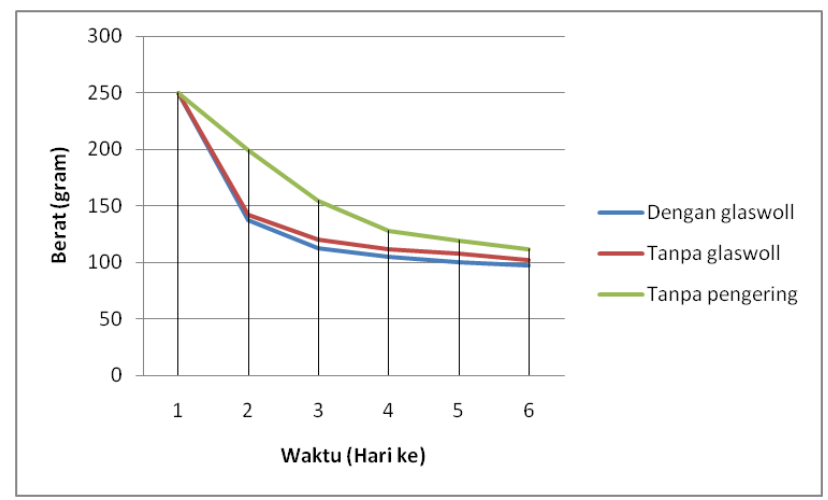

Gambar 3. Grafik hasil pengukuran berat biji kopi cokelat

Selama 5 hari pengeringan, pengeringan menggunakan alat pengering tambahan glaswoll, berat akhir biji kopi cokelat adalah 97 gram dengan rata-rata pengurangan berat setiap harinya adalah 30,6 gram. Pengeringan menggunakan alat pengering tanpa glaswoll berat akhir biji kopi cokelat adalah 102 gram gram dengan rata-rata pengurangan berat setiap harinya adalah 29,6 gram. Pengeringan tanpa menggunakan alat pengering berat akhir biji kopi cokelat adalah 112 gram dengan rata-rata pengurangan berat setiap harinya adalah 26,6 gram.

Pada grafik di atas, jika dibandingkan antara pengeringan menggunakan alat pengering dengan pengeringan tanpa menggunakan alat pengering maka bisa dikatakan bahwasanya pengeringan 5 hari tanpa alat setara dengan pengeringan 3 hari dengan menggunakan alat. Hal ini menunjukkan efisensi waktu untuk menghasilkan produk dari proses pengeringan, jadi akan menghemat waktu pengeringan jika suatu proses pengeringan menggunakan alat pengering.

Jika dilihat dari sudut pandang kualitas hasil akhir produk biji kopi cokelat yang telah dilakukan pengeringan, maka biji kopi cokelat yang dikeringkan dengan menggunakan alatlah (menggunakan tambahan glaswoll maupun tanpa menggunakan glaswoll) yang mutu kualitasnya lebih bagus dibandingkan dengan kualitas biji kopi cokelat yang dikeringkan tanpa pengering, dikarenakan sistem panas yang digunakan alat pengering adalah menggunakan aliran konveksi udara dari kolektor dan tidak langsung menggunakan radiasi matahari, dalam kotak pengering juga terhindar dari kotoran-kotoran luar yang bisa merusak kualitas bahan yang dikeringkan. Kualitas biji yang dikeringkan mempengaruhi harga hasil jual biji kopi cokelat, jadi pengeringan dengan menggunakan alat mampu menambah pendapatan para petani biji kopi cokelat.

\section{KESIMPULAN}

Telah dirancang bangun sebuah alat pengering dengan menggunakan kolektor surya, yang telah didesain dengan tambahan glaswoll pada bagian bawah kolektor dan cermin di kedua sisi kolektor sebagai pemantul radiasi cahaya matahari yang mampu meningkatkan kualitas hasil dari manfaat pengering tersebut. 
Temperatur maksimum yang dihasilkan oleh alat pengering dengan tambahan glaswoll didapat dengan menggunakan sudut kemiringan kolektor $75^{\circ}$, yaitu kotak pengering mengalami penguatan temperatur sebanyak 207,50\% dibanding temperatur luar. Temperatur maksimum yang dihasilkan oleh alat pengering tanpa tambahan glaswoll didapat dengan menggunakan sudut kemiringan kolektor $75^{\circ}$, yaitu kotak pengering mengalami penguatan temperatur sebanyak $201,80 \%$ dibanding temperatur luar.

Hasil biji kopi cokelat yang sudah dikeringkan dengan menggunakan alat pengering mempunyai nilai kualitas lebih bagus daripada pengeringan tanpa menggunakan alat pengering, kualitas pengeringan sangat mempengaruhi harga jual biji kopi cokelat di pasaran, jadi penggunaan alat pengering mampu menambah penghasilan petani biji kopi cokelat.

\section{DAFTAR PUSTAKA}

[1] Abdullah, Kamarudin dkk. 1998. Energi dan Listrik Pertanian. Bogor: Institut Pertanian Bogor.

[2] Ekechukwu, O.V., Norton, B. (1999), Review of Solar-Energy Drying Systems I: an Overview of Drying Principle and Theory, International Journal of Energy Conversion \& Management.

[3] Koestoer, Raldi Artono.2002. Perpindahan Kalor. Jakarta: Salemba teknik. 